\title{
EVALUATION OF IN VITRO ANTHELMINTIC PROPERTIES OF AVICENNIA MARINA LEAVES
}

\author{
GANA MANJUSHA KONDEPUDI*
}

Department of Pharmacognosy and Phytochemistry, Vignan Institute of Pharmaceutical Technology, Besides Vsez, Kapujaggraju Peta Duvvada, Visakhapatnam, Andhra Pradesh, India. Email: manjusha.kondepudi.g@gmail.com

Received: 10 November 2017, Revised and Accepted: 11 January 2018

ABSTRACT

Objectives: The purpose of the present study was to determine the anthelmintic properties of chloroform, methanol and aqueous extracts of Avicennia marina leaves on Indian earthworm- Pheretima posthuma.

Methods: Three concentrations of each extract $(25 \mathrm{mg} / \mathrm{ml}, 50 \mathrm{mg} / \mathrm{ml}$, and $75 \mathrm{mg} / \mathrm{ml}$ ) were studied in this activity to determine the time of paralysis (vermifuge) and the time of the death of the worms (vermicidal). Piperazine citrate in the same concentrations was taken a reference standard and normal water was taken as control. The time taken for paralysis and death of the worms was recorded.

Results: All the extracts showed dose-dependent and a significant activity was shown at higher concentration (75 mg/ml). Methanolic extract showed peak activity at a concentration of $75 \mathrm{mg} / \mathrm{ml}$.

Conclusion: Based on the results it was found that the leaves of $A$. marina possess vermifuge and vermicidal activities and can be used as an effective anthelmintic.

Keywords: Anthelmintic, Mangroves, Pheretima posthuma, Vermifuge, Vermicide.

(C) 2018 The Authors. Published by Innovare Academic Sciences Pvt Ltd. This is an open access article under the CC BY license (http://creativecommons. org/licenses/by/4. 0/) DOI: http://dx.doi.org/10.22159/ajpcr.2018.v11i4.23605.

\section{INTRODUCTION}

Medicinal plants are known to play a key role in the management of various diseases especially in areas where affordability and availability of Western medicines are remarkably low. In fact plants have been used as therapeutic agents since ages [1]. Therefore, aiming for drugs from plants and animals is always of greater interest and continuous process for research [2]. Mangroves are special woody trees found on sheltered coast lines and river deltas, growing in brackish wetlands between land and sea where other plants cannot survive. Highly stressful habitat involving daily changes in $\mathrm{p}^{\mathrm{H}}$ of soil and water, humidity, salinity, temperature, and tidal cycles may be the possible reasons for many of these plants to synthesize enormous bioactive phytoconstituents many of which have been found to have extensive use in industry and human health care. Traditionally more than 100 numbers of mangroves and their associated plants were used in the treatment of various ailment but only a few are evaluated and documented [3]. Avicennia marina is one of the most common species in mangrove vegetations, commonly known as gray mangroves belongs to the family Acanthaceae (Avicenniaceae) [4]. A. marina has been used as traditional medicine for years with a variety of biological activities such as antioxidant, antibacterial, antifungal, antiulcer, antiplasmodial, antitumor, and anticancer properties.

Helminth infections are among the most widespread infections in humans distressing a huge population of the world [5]. In general, majority of Helminth infections are restricted to tropical regions and become a hazard to health by contributing to the prevalence of undernourishment, anemia, eosinophilia, and pneumonia [6]. Parasitic diseases cause ruthless morbidity affecting the population in endemic areas [7]. The gastrointestinal helminthes become resistant to currently available synthetic anthelmintic drugs. Hence, the need to investigate and identify natural substances with anthelmintic activity is huge $[8,9]$. The present study was aimed at using mangroves in the control of intestinal parasites.

\section{MATERIALS AD METHODS}

Collection of plant material

The plant was locally called Tella mada. The leaves of $A$. marina were collected from Coringa Wildlife sanctuary, Kakinada, Andhra Pradesh, India. The plant was botanically identified and authenticated in the Department of Botany, P.R. Government College, Kakinada.

\section{Preparation of extracts}

Freshly collected leaf material was washed thoroughly and shade dried at room temperature, coarsely powdered and subjected to successive extraction using chloroform, methanol, and water and concentrated under vacuum to get the corresponding residues.

\section{Drugs and chemicals}

All the chemical and reagents procured were of the Analytical grade. The drug Piperazine citrate (Glaxosmithkline) was used during the experimental protocol.

\section{Preliminary phytochemical screening}

The preliminary phytochemical screening of the extracts revealed the presence of steroids, glycosides, flavonoids, and tannins.

\section{Experimental animals}

Earthworms have been selected for the initial evaluation of anthelmintic activity because of their easy availability and their anatomical and physiological resemblance with the intestinal helminthes of humans [10-12]

Pheretima posthuma was collected from the water logged areas of soils and washed with normal saline to remove filthy matter. They were authenticated in the Department of Zoology, P.R. Government College, Kakinada.

\section{Ethics approval}

The experiments conducted on the animals are performed in accordance with the approval of Institutional Animal Ethics Committee 
Table 1: Each value represents mean $\pm \operatorname{SD}(n=6)$

\begin{tabular}{llll}
\hline Group & Concentration $(\mathbf{m g} / \mathbf{m l})$ & Time taken for paralysis $(\mathbf{P})$ in $\mathbf{m i n}$ & Time taken for death $(\mathbf{D})$ in $\mathbf{m i n}$ \\
\hline Control (water) & - & - & - \\
Chloroform leaf extract & 25 & $42.63 \pm 0.98$ & $107.16 \pm 1.64$ \\
& 50 & $35.27 \pm 0.57$ & $72.90 \pm 1.63$ \\
Methanolic leaf extract & 75 & $15.45 \pm 0.46$ & $65.90 \pm 0.64$ \\
& 25 & $35.92 \pm 0.44$ & $52.37 \pm 1.82$ \\
& 50 & $25.31 \pm 0.65$ & $41.54 \pm 1.05$ \\
Aqueous leaf extract & 75 & $13.98 \pm 0.94$ & $33.49 \pm 0.69$ \\
& 25 & $62.15 \pm 1.06$ & $108.83 \pm 2.49$ \\
Standard (Piperazine citrate) & 50 & $35.86 \pm 0.60$ & $81.59 \pm 0.77$ \\
& 25 & $24.66 \pm 0.69$ & $74.79 \pm 0.61$ \\
& 50 & $30.61 \pm 0.66$ & $53.56 \pm 0.86$ \\
& 75 & $26.58 \pm 0.93$ & $28.55 \pm 0.79$ \\
\end{tabular}

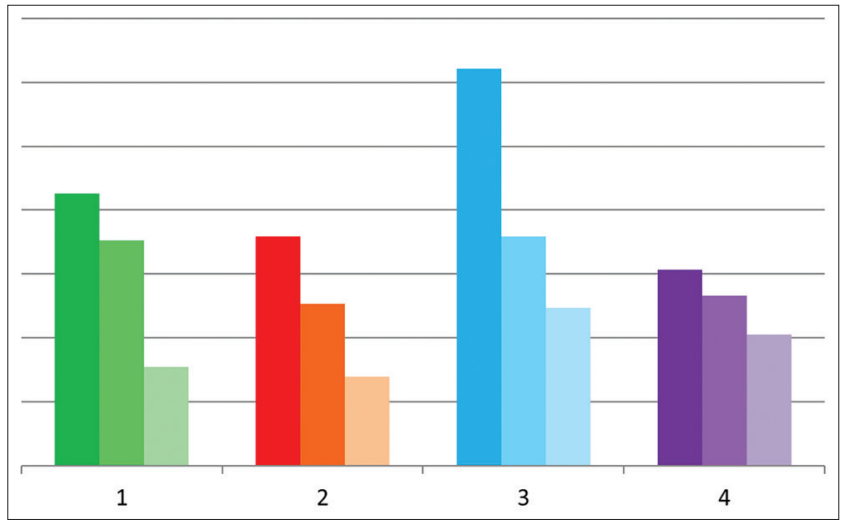

Fig. 1: Dose-dependent activity

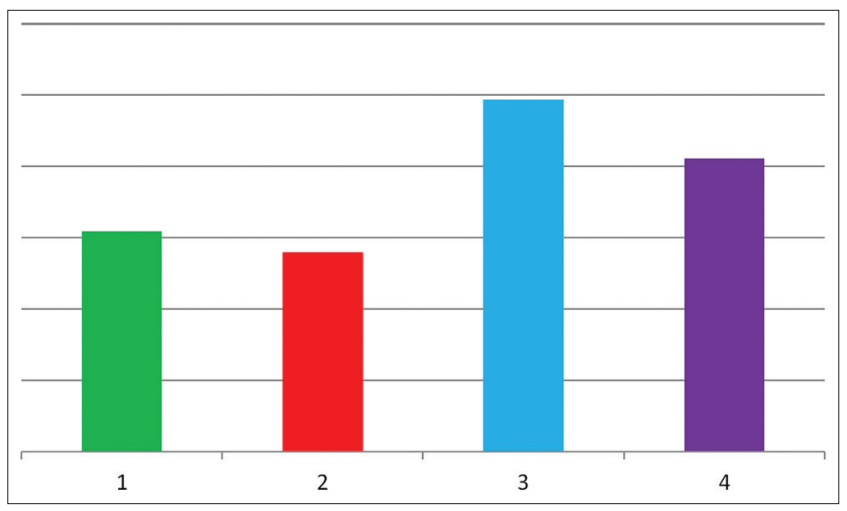

Fig. 2: Time taken for paralysis of the worms at highest concentration $(75 \mathrm{mg} / \mathrm{ml})$

(1275/ac/09/CPSCEA) as per the guidelines given by CPCSEA on animal experimentation.

\section{Anthelmintic activity}

The anthelmintic assay was carried out as per the method of Ajaiyeoba et al. $[13,14]$. The Indian earthworms were divided into three groups each containing six earthworms approximately equal size was selected for the experiment. A stock solution was prepared from the dried extract and different concentration $(25,50$, and $75 \mathrm{mg} / \mathrm{ml})$ were made from it, distilled water (control) and reference standard Piperazine citrate (25, 50 , and $75 \mathrm{mg} / \mathrm{ml}$ in distilled water) taken for the study. The worms were then placed in Petri dish containing $25 \mathrm{ml}$ of test sample and standard. The time taken to paralysis and death of the individual worms was recorded. The time taken to paralysis is noted when movement is observed only after vigorous shaking. Time taken for the death of worms was recorded after ascertaining that the worms neither moved

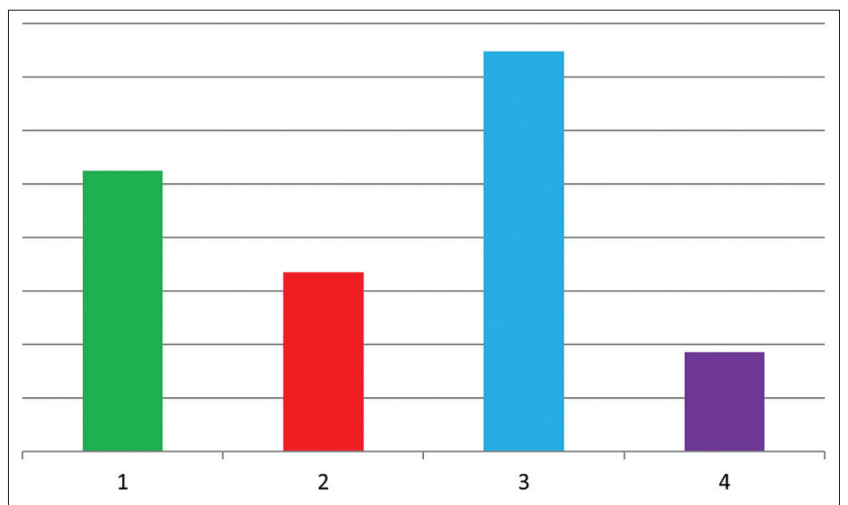

Fig. 3: Time taken for the death of the worms at highest concentration $(75 \mathrm{mg} / \mathrm{ml})$. (1) Chloroform leaf extract, (2) methanolic leaf extract, (3) aqueous leaf extract, (4) standard (piperazine citrate)

when shaken vigorously nor revive when dipped in normal saline. All the results were shown in Table 1.

\section{RESULTS}

Preliminary phytochemical screening

Preliminary phytochemical screening of the extracts revealed the presence of steroids, glycosides, flavonoids, and tannins.

\section{Anthelmintic activity}

The crude extract of the leaves of $A$. marina produced a significant anthelmintic activity in a dose-dependent manner as shown in Table 1 and Fig. 1.

\section{DISCUSSIONS}

From the observations made higher concentrations of extracts produced the paralytic effect much earlier and the time taken for death was shorter for all worms. The peak anthelmintic activity was exhibited by the methanolic extract at the highest concentration $(75 \mathrm{mg} / \mathrm{ml})$ which takes $13.98 \pm 0.94 \mathrm{~min}$ for paralysis and $33.49 \pm 0.69 \mathrm{~min}$ for the death of the worms, followed by the aqueous extract which takes $24.66 \pm 0.69 \mathrm{~min}$ for paralysis and $74.79 \pm 0.61 \mathrm{~min}$ for the death of the worms (Figs. 2 and 3). Chloroform extract exhibits less activity in comparison to other extracts. The leaves of $A$. marina shows promising anthelmintic activity as the other medicinal plants which are being explored for anthelmintic activity.

\section{CONCLUSION}

The present study is designed to determine the effect of various extracts prepared from A. marina leaves. To the best of our knowledge, it is the first time that the leaves of $A$. marina were tested for anthelmintic 
activity. In accordance with the results obtained it is concluded that the A. marina showed significant anthelmintic activity. The plant may be further explored to recognize the active chemical constituent responsible for the anthelmintic activity. If done it will be helpful to the natives living in tidal forests who cannot afford expensive synthetic anthelmintic drugs.

\section{ACKNOWLEDGMENT}

My heartfelt thanks to Dr. Y. Srinivas Rao, Principal, Vignan Institute of pharmaceutical Technology, Visakhapatnam, for providing facilities to carry out the research work. Special thanks to Prof B Ganga Rao, Andhra University, Visakhapatnam, Dr.N. Anbalagan, Principal, Pydah College of Pharmacy, Kakinada, for helping me in the identification and authentication of the plant material and animals.

\section{AUTHOR'S CONTRIBUTION}

I am solely responsible for the planning, conductance of study, interpretation of results and writing

\section{CONFLICT OF INTEREST}

Do not have any conflicts of interest to include.

\section{REFERENCES}

1. Atolani O, Olatunji GA. Comprehensive scientific demystification of Kigelia Africana: A review. Afr J Pure Appl Chem 2009;3:158-64

2. Iswariya S, Uma TS. Evaluation of in vitro anti-inflammatory and antimicrobial activity of aqueous and methanolic seed extracts of Citrullus lanatus. Int J Pharm Pharm Sci 2017;9:29-3
3. Bandaranayake WM. Traditional and medicinal uses of mangroves. Mangroves Salt Marshes 1998;2:133-48.

4. Duke NC. A systematic revision of mangroves genus Avicennia (Avicenniaceae) in Australia. Aust Syst Bot 1991;4:299-24.

5. Kosalge SB, Fursule RA. Investigation of in vitro Anthelmintic activity of Thespesia lampas (cav.). Asian J Pharm Clin Res 2009;2:69-71.

6. Bundy DA. Immunoepidemiology of intestinal helmintic infection I: The global burden of intestinal nematode disease. Trans Royal Soc Trop Med Hyg 1994;8:259-61.

7. Tagbota S, Townson S. Antiparasitic properties of medicinal and other naturally occurring products. Adv Parasitol 2001;50:199-5.

8. Olounlade'PA, Azando EV, Hounzangbe'-adote' MS, Ha TB, Leroy E, Moulis $\mathrm{C}$, et al. Inivitro anthelmintic activity anthelmintic activity of the essential oils of Zanthoxylum zanthoxyloides and Newbouldia laevis against Strongyloides ratti. Parasito Res 2012;110:1427-33.

9. Mehlhorn H, Al-Quraishy S, Al-Rasheid KA, Jatzlau A, Abdel-Ghaffar F. Addition of combination of onion (Allium cepa) and coconut(Cocos nucifera) to food of sheep stops gastrointestinal infections. Parasito Res 2010;108:1041-6.

10. Vigar Z. Atlas of Medical Physiology. $2^{\text {nd }}$ ed. Singapore: P.G. Publishing House; 1984.

11. Dash GK, Suesh P, Kar DM, Ganapaty S, Panda SB. Evaluation of Evolvulus alsinoides Linn. For anthelmintic and antimicirobial activities. J Nat Rem 2002;2:182-5.

12. Jayaramu SC, Prathiba M. Evaluation of in vitro antihelmintic properties of the extract of Russelia equisetiformis (schlecht and cham) scrophulariaceae. Int J Pharm Pharm Sci 2016;8:459-61.

13. Ajaiyeoba EO, Onocha PA, Olarenwaju OT. In vitro anthelmintic properties of Buchholzia coriaceae and Gynandropis gynandra extract. Pharm Biol 2001;39:217-20.

14. Deb PK, Ghosh R, Das S, Bhakta T. In vitro anthelmintic activity of Acorus calamus leaves. Asian J Pharm Clin Res 2013;6:135-7. 